University of Nebraska - Lincoln

DigitalCommons@University of Nebraska - Lincoln

1989

\title{
Shooting yourself in the foot with due care: psychotherapists and crystallized standards of tort liability
}

Robert F. Schopp

University of Nebraska-Lincoln, rschopp1@unl.edu

David B. Wexler

Follow this and additional works at: https://digitalcommons.unl.edu/lawfacpub

Part of the Legal Studies Commons

Schopp, Robert F. and Wexler, David B., "Shooting yourself in the foot with due care: psychotherapists and crystallized standards of tort liability" (1989). College of Law, Faculty Publications. 97.

https://digitalcommons.unl.edu/lawfacpub/97

This Article is brought to you for free and open access by the Law, College of at DigitalCommons@University of Nebraska - Lincoln. It has been accepted for inclusion in College of Law, Faculty Publications by an authorized administrator of DigitalCommons@University of Nebraska - Lincoln. 


\section{Shooting yourself in the foot with due care: psychotherapists and crystallized standards of tort liability}

BY ROBERT F. SCHOPP, PH.D., J.D., PH.D. AND DAVID B. WEXLER, J.D.

This paper discusses a conceptual tension that arises from the attempt to regulate the fiduciary therapeutic relationship through the law of negligence. This tension becomes particularly problematic when courts adopt crystallized duties as per se rules or as presumptive standards of care for psychotherapists. Under certain conditions, this tension can undermine the therapeutic process, the fiduciary nature of the therapeutic relationship, and the process by which professional organizations promulgate guidelines for their members. Thus, under certain circumstances, regulation through negligence law may frustrate both therapeutic and legal purposes. This paper suggests steps that courts and professional organizations can take to minimize the insidious effects of this tension, but it does not contend that these steps will resolve all of the difficulties associated with tort regulation of psychotherapy.

Professional organizations sometimes promulgate guidelines intended to inform their members' practice. These standards may be designed to guide practitioners under ordinary condi-

AUTHORS' NOTE: We are grateful to Barbara Hannan and Robert $D$. Miller for helpful comments on earlier drafts of this paper.

(C) 1990 by Federal Legal Publications, Inc. 
tions, or they may define an ideal toward which to strive. If courts adopt idealized standards as criteria of responsible practice for the purpose of establishing tort liability, professional organizations might respond by refraining from developing such guidelines or by framing them with an eye toward preventing liability rather than strictly for the purpose of enhancing patient care. In either case, the courts' actions and the organizations' responses might hinder, rather than enhance, the therapeutic project of the mental health system.

Therapeutic jurisprudence is an approach to the study of mental health law that investigates the effects of the law on the therapeutic project of the mental health system and considers ways in which the law might be designed in order to promote that project without sacrificing other important values. One important item on this agenda is the study of various ways in which legal rules, procedures, or roles may actively impair the functioning of the mental health system. ${ }^{1}$ This paper considers one aspect of tort law that may undermine both the therapeutic project of the mental health system and the legal goals that the law is designed to promote.

Negligence law is intended to serve at least two purposes. First, it provides compensation to those who suffer injury as a result of unreasonably risky conduct by others; second, it promotes reasonable care by actors who engage in potentially dangerous conduct. It is intended to promote reasonable care by shifting the cost of loss due to unreasonably risky behavior to the actor, thus motivating actors to avoid such unreasonable conduct. An actor is found liable for negligent behavior when that actor causes injury to another by virtue of his failure to exercise the care of a hypothetical reasonable person in the same or similar circumstances. When the action in question involves the practice of a profession, the actor must act with the care and competence of an ordinary competent practitioner of that profession. ${ }^{2}$ 
Unfortunately, courts must evaluate behavior, consider standards of care, and make negligence determinations retrospectively. Professionals, including clinicians, must practice their professions in a manner that they consider responsible and hope that if injury occurs, courts and juries will agree retrospectively with their prospective evaluation of reasonable care. This prospect is particularly troublesome in light of the literature suggesting the substantial effect of hindsight bias. Judges and juries must decide whether certain decisions and actions by practitioners were reasonable under the circumstances that prevailed when the clinicians decided and acted. However, judges and juries make these determinations with knowledge of the eventual results of the clinicians' action, while the clinicians decided to engage in their conduct without the benefit of such information. The literature suggests that a court's knowledge about the results of the conduct in question may substantially affect its evaluation of the action's reasonableness, although the practitioner selected the course of action without access to such information. $^{3}$

Legal institutions could address the hindsight bias through both procedural and substantive steps. Procedurally, for example, expert witnesses might testify during the malpractice trial about the existence and robustness of the hindsight bias and about debiasing techniques. Such testimony would be intended to educate the jury about the bias and, hopefully, to influence them toward less biased decision-making. ${ }^{4}$ Alternately, the judge might inform the jury about the bias and about debiasing techniques through jury instructions. ${ }^{5}$ Some have even suggested that courts bifurcate malpractice proceedings, requiring that the jury determine the negligence issue before receiving information regarding the outcome of the clinician's decision for the purpose of evaluating proximately caused harm and damages. ${ }^{6}$ 
In addition to these procedural measures, courts and professional organizations might jointly address the hindsight bias by establishing relatively predictable substantive standards of professional practice. Courts could adopt crystallized standards of due care for negligence purposes such that a practitioner could predict that certain practices would be accepted as reasonable under certain circumstances. Alternately, courts could adopt presumptive standards that would enable the clinician to predict that conduct conforming to those standards would raise a presumption of due care, placing the burden on the other party to override this presumption. Either alternative might reasonably be expected to enable the practitioner to predict with some confidence a court's conception of due care and, thus, to conform to that standard.

Consider, for example, the administration of electroconvulsive therapy (ECT). A recent study indicates that administration of ECT in Massachusetts varies widely from guidelines published by a task force of the American Psychiatric Association but that malpractice suits in this area are rare.? Courts might attempt to establish consistent standards of care in this area by adopting the task force's recommendations as crystallized rules of due care for malpractice, accepting evidence that ECT had been administered contrary to guidelines regarding age, diagnosis, or procedure as conclusive or presumptive evidence of malpractice. Conversely, conformity with the guidelines would establish due care. Such a practice by the courts would probably promote both consistency of practice and predictability regarding liability for practitioners.

This paper will examine several areas of mental health law in which some relatively crystallized standards have developed. It will argue that: (1) the appropriate role of crystallized standards of negligence in the tort regulation of clinical practice is quite limited and (2) the application of negligence law to mental health practitioners, and possibly to the 
members of several other professions, raises a fundamental tension that pervades the entire enterprise and, under certain conditions, renders the process self-defeating.

The argument will proceed in the following manner. Section I will briefly review the relevant principles of negligence law and identify some areas of mental health law in which relatively crystallized standards have begun to develop. Section II will examine three difficulties encountered when negligence law is applied to psychotherapy, and it will explicate the fundamental tension that underlies them. Section III will discuss the ramifications of these issues for tort regulation of psychotherapy, with particular attention to the appropriate role of crystallized standards. Finally, section IV will briefly summarize the conclusions and recommendations of the paper. ${ }^{8}$

\section{Negligence and crystallized duties}

A. Principles of negligence
The law of torts regulates ordinary social activity by distributing the cost of such activity according to certain social goals, policies, and conceptions of fault. Negligence law shifts the cost of injury suffered as a result of human action from the victim to the actor when that injury results from a lack of reasonable care on the part of the actor. In establishing standards of due care, the courts balance the plaintiff's interest in compensation for loss, the defendant's interest in engaging in the type of activity involved, and society's interest in promoting productive activities while regulating risks. ${ }^{9}$ Thus, the court applies a cost-benefit analysis to the type of activity in question, balancing the social benefit in encouraging such activity against the social cost it produces. ${ }^{10}$

In setting the standard of care for a particular type of conduct, courts attempt to guide the behavior of future actors through the process of stare decisis. Each case contributes to a body of precedent that informs future courts of the 
appropriate standard to apply. Thus, future actors are expected to guide their behavior according to the standards of reasonableness established by previous cases. "If a particular type of activity produces relatively little social benefit at the cost of great risk, then a reasonable person would be expected to engage in that activity with great care, if at all. In contrast, a highly productive activity that creates relatively little risk does not require similar vigilance to prevent injury.

The usual standard of care for negligence cases is that of the ordinary prudent person under the same or similar circumstances, where the circumstances are evaluated in terms of the risk-benefit analysis described above. ${ }^{12}$ That is, the actor is held to the degree of care that the ordinary prudent person would exercise in light of the risks and benefits involved. However, if an individual possesses, or claims to possess, superior skill or knowledge, the courts apply an elevated standard. Members of a profession, therefore, must perform with the ordinary care and competence (OCC) of a member in good standing of that profession. ${ }^{13}$

The application of this OCC standard to particular cases generally requires expert testimony to establish the appropriate practice according to accepted professional standards of care under circumstances similar to those which occurred in these cases. This process requires that the courts engage in case-by-case retrospective evaluations of the professionals' conduct in the circumstances. This produces uncertainty in practice, as the clinical decision must be made before the court determines what conduct it will accept as reasonable in this particular situation. This uncertainty is particularly problematic in light of the dangers of hindsight bias. ${ }^{14}$

Under certain conditions, relatively fixed rules of liability regarding identified types of professional practice can crystallize in the law of negligence. Trial courts may treat appellate decisions that describe certain conduct as clearly negligent, as clearly not negligent, or as falling within the 
scope of jury evaluation as establishing rules of reasonable conduct for that type of activity. ${ }^{15}$ For example, the Supreme Court of Washington has established a per se standard of negligence for ophthalmologists who fail to administer a pressure test for glaucoma. ${ }^{16}$ Courts may also interpret statutes that require or prohibit certain kinds of conduct as establishing standards of reasonable behavior for negligence cases. Criminal or regulatory statutes, for example, might require or forbid particular types of activity. Courts may treat violations of these statutes as negligence per se, as presumptive evidence of negligence, or merely as relevant evidence regarding the appropriate standard of care. ${ }^{17}$ When rules of reasonable care crystallize into relatively fixed standards of negligence per se or presumptive negligence, actors may be able to select with more confidence behavior that will constitute due care.

- Crystallized duties and clinicians

Some crystallized duties apply to professionals generally, including mental health clinicians. These include the following duties: to maintain competence regarding new developments in the field; to decline a case or responsibility for which the practitioner is not qualified; and to refer to an expert or specialist when such a referral is called for. In addition, certain behavior by members of a particular profession may become established as negligence per se. For example, the surgeon who closes an incision without removing all surgical implements or the attorney who fails to file an action within the statute of limitations may be held to have violated a per se standard of care. ${ }^{18}$

Some crystallized duties that are specifically directed toward mental health clinicians have also begun to develop. In one case, the court ruled that non-expert testimony that a therapist had physically beaten the patient established a prima facie case of malpractice that did not require any additional evidence regarding the standard of care in the profession. ${ }^{19}$ 
At least one commentator contends that courts will generally accept physical invasion of the patient as improper practice per se..$^{20}$ Other commentators have concluded that courts will likely hold that sexual relationships between clinicians and their patients are per se violations of the therapist's duty to the patient. ${ }^{21}$

While the crystallized duties described above elicit relatively little dissent, the Tarasoff court's "duty to protect" has been much more controversial. In Tarasoff, the court found the therapists liable for failing to warn their patient's victim that the patient presented a threat to her safety. ${ }^{n}$ The court did not merely find that this particular failure to warn was negligent under the circumstances. Rather, the court articulated a crystallized duty to protect potential victims when the therapist determines or should have determined that the patient presents a danger to others. The therapist's duty "may call for him to warn the intended victim or others likely to apprise the victim of the danger, to notify the police, or to take whatever steps are reasonably necessary under the circumstances." ${ }^{23}$

On the surface, the Tarasoff holding may not appear to constitute a crystallized standard because the court articulated a duty to take any appropriate steps to protect potential victims. Two factors render it prudent, however, for any therapist in a Tarasoff jurisdiction to interpret the case as establishing a crystallized duty to warn. ${ }^{24}$ First, the court specified that this duty applies when there is an identified or readily identifiable victim. ${ }^{25}$ Plausible protective steps such as increasing the frequency of therapy, focusing therapeutic efforts on defusing the patient's anger, reviewing medication, or notifying the police do not, however, require an identifiable victim. The requirement of an identifiable victim seems to make sense only if the duty is understood as a duty to warn. Second, the Tarasoff therapists took other steps, including the court's recommended one of notifying police, to prevent harm. However, the court found the therapists 
liable, despite these steps, for failing to warn. The prudent therapist would conclude from these two factors that protective steps other than warnings will be accepted as adequate to meet the standard of care only if they are successful. For these reasons, this paper will treat the Tarasoff standard as a crystallized duty to warn. ${ }^{26}$

While the Tarasoff case established a crystallized duty through an appellate court decision directly addressing the appropriate standard of care for negligence, courts can also establish relatively crystallized standards of care in decisions that do not directly address clinician negligence. In Wyatt $v$. Stickney, the court entered consent decrees establishing standards of care for adequate treatment and habilitation of the mentally ill and retarded in Alabama state institutions. ${ }^{27}$ The standards of adequate treatment for the mentally ill prohibit treatment plans that include work that is part of hospital maintenance unless the patient is paid at minimum wage. ${ }^{28}$ The standards of adequate habilitation of the mentally retarded allow behavior modification programs that employ aversive stimuli only with the consent of both the patient and the guardian. ${ }^{29}$ Similarly, in Rogers $v$. Okin the trial court ruled that patients can be forcibly medicated or secluded only when failure to do so would result in physical harm to the patient, other patients, or the staff..$^{30}$

In each of these cases, courts established standards of adequate care for certain types of circumstances. If future courts accept these findings as establishing either per se or presumptive criteria of due care for the purpose of malpractice, then clinicians can guide their clinical practice according to these standards with some confidence that doing so protects them from malpractice judgments. Under these circumstances, it is reasonable to expect that clinicians who are aware of these decisions will treat them as rules or guidelines for practice. 
While the Rogers trial court set specific criteria for involuntary medication or seclusion, the appellate court rejected this approach. It ruled that medication can be forcibly administered only after balancing the need to prevent violence against possible harm to the patient, but it placed the responsibility for evaluating each situation in the hands of qualified physicians. ${ }^{31}$ This decision leaves the clinician considerable latitude to exercise independent judgment, but it provides less predictable guidance than would a finding establishing an explicit criterion. In Youngberg v. Romeo, the Supreme Court adopted an approach to clinical seclusion or restraint decisions that grants considerable deference to professional judgment:

[T] he decision, if made by a professional, is presumptively valid; liability may be imposed only when the decision by the professional is such a substantial departure from accepted professional judgment, practice, or standards as to demonstrate that the person responsible actually did not base the decision on such a judgment. ${ }^{32}$

When viewed in isolation, decisions that defer to professional judgment regarding appropriate care appear to leave clinicians with greater latitude in their treatment decisions at the expense of predictability regarding criteria of liability. Court decisions that defer to professional judgment may actually establish relatively crystallized duties, however, if courts also accept published professional standards or guidelines as establishing appropriate clinical judgment. In some areas, for example, courts have relied heavily on standards published by professional organizations regarding staffing or psychological testing to establish criteria of acceptable professional judgment. ${ }^{33}$

When courts defer to professional judgment regarding appropriate practice but accept the guidelines published by professional organizations as definitive of responsible professional judgment, then these guidelines can effectively establish crystallized standards of due care for members of the profession. Professional organizations, and their legal 
consultants, have recognized the legally protective function that professional standards and guidelines can serve: "Of course, the drafting of standards may help codify good clinical practice. If standards are promulgated and followed, the mere act of following them should, under Romeo's 'presumptive validity' test, go a long way toward insulating professionals from legal liability." 34 These organizations also recognize, however, that such standards-and courts' deference to them-can serve as a double-edged sword: "The other side of the coin, however, is that if written standards are viewed as an embodiment of accepted professional judgment rather than as an embodiment of how practice may operate under ideal conditions, a professional's substantial departure from the standards . . . may pave the way toward possible liability." "3s

In summary, courts can independently create relatively crystallized standards of care for malpractice liability-directly by articulating specific duties in malpractice cases, or indirectly by setting standards of acceptable care for institutions. Alternately, courts can establish crystallized duties by adopting standards promulgated by professional organizations as definitive of reasonable care. If courts then consistently apply these standards in malpractice cases, they have effectively established crystallized duties.

One can understand various approaches to malpractice litigation as occurring along a continuum of crystallization. At the crystallized pole stand the fully crystallized duties. Violations of these standards constitute negligence per se. Physical invasions, sexual relationships, and the Tarasoff duty to warn arguably stand at or near this pole. The traditional OCC standard constitutes the opposite end of the continuum. At this pole, standards of due care under the circumstances are established by professional testimony in each case. Decisions that accept professional guidelines as relevant evidence regarding the standard of care would fall along the continuum according to the weight granted to those guide- 
lines. If a court accepted such guidelines as presumptive evidence of due care (or failure to exercise due care), then it would fall relatively near the crystallized pole.

Approaches that fall near the crystallized pole leave relatively little room for professional judgment in clinical practice, but they provide clinicians with more predictability regarding tort liability. In contrast, the OCC standard allows greater latitude for judgment at the expense of less predictability. Arguably, clinicians would be better able to protect themselves from unexpected liability if courts were to establish more crystallized duties or if professional organizations published clear guidelines for clinical practice and courts accepted these publications as presumptive standards of due care. Such crystallized duties are problematic for at least three reasons, however, when they are applied to clinical practice.

\section{Crystallized duties and mental health practice}

A. Conflicts One of the general purposes of tort law is to encourage of interest people to behave in a manner that protects the interests of others. When negligence law is applied to driving, for example, it is intended partially to encourage drivers to drive with reasonable care, and thus to protect other motorists and pedestrians from unreasonable risk. When applied to clinical practice, negligence law is intended to encourage professionals to practice in a manner that protects and promotes the interests of their clients and the public. While the law of professional negligence directs the professional's attention toward the interests of his clients and the public, it does so indirectly. That is, negligence law attaches liability to certain types of conduct in order to motivate the practitioner to refrain from engaging in that behavior by rendering such conduct contrary to his own self-interest. The behaviorguiding purpose of tort law rests on the implicit premise that courts can generally attach liability to conduct in such a 
manner as to cause the potential tortfeasor's interests to converge with the interests of others. By holding defendants liable for behavior that creates unreasonable risks for others, courts attempt to motivate actors through appeal to their self-interest to act in a manner that protects the interests of others.

Crystallized duties set a prospective standard of care for a general class of situations. Given this crystallized duty, it is in the clinician's interest to conform to it in any situation that falls within the scope of that class. For example, if courts adopt a standard of care that categorizes sexual relationships with patients as malpractice per se, then it is in the clinician's interest to refrain from sexual relationships with any patient. As long as the conduct required by the crystallized duty is consistent with the interests of the patient or the public, negligence law promotes its intended purpose. If particular circumstances arise, however, in which the conduct required by the per se rule does not promote the interests of the client or the public, then the implicit premise of negligence fails. In these cases, the crystallized standard causes the interests of the clinician to diverge from those of the client or the public.

There are at least two ways in which such a divergence can motivate a clinician to act in a manner contrary to the purpose that the standard was designed to promote. First, cases might arise in which the crystallized duty applies, and the clinician can best protect himself from liability by conforming to that standard despite his judgment that doing so will not promote the interests of his patient or the community. Consider the following hypothetical cases.

Smith is a 55-year-old widower. Prior to his first hospitalization approximately two and one-half years ago, he had received periodic outpatient treatment for anxiety and depression, but he had worked consistently as a heating and air conditioning repair man. He had not suffered major psychopathology or required inpatient care. His wife died three years ago, and a few months after her death Smith was hospitalized for treatment of a major depressive 
disorder with suicidal ideation and markedly increased anxiety. His depression and anxiety improved significantly within six months of hospitalization, and discharge planning began at that time.

Several planned placements in group homes and boarding houses have been canceled, however, because Smith experienced exacerbated anxiety as the discharge became imminent. This anxiety appears to be a direct result of his need to return to work when discharged and his fear that he has lost his technical skills. Smith and the treatment team agree that Smith would benefit most from a period during which he would work for the hospital maintenance department in order to improve his confidence by practicing his old skills. Although all parties agree that by doing so Smith would provide a service for which the hospital usually pays employees, both union contracts and budgetary constraints preclude paying Smith for such work. Smith would welcome the opportunity to work without compensation, but writing and administering such a treatment program would violate the Wyatt standard. ${ }^{36}$ The psychologist's interest in avoiding liability seems to diverge from Smith's interest.

Jones is a 20-year-old moderately retarded resident of the state hospital. She has an extended history of episodic assaultive and self-injurious behavior. The latter usually takes the form of severe head-banging in response to situations in which others fail to meet her demands. Consequently she has developed extensive scar tissue on her forehead, and each additional episode results in further lacerations. Various nursing care plans and programs of differential reinforcement have proved unsuccessful in eliminating this behavior.

One night following an episode of head-banging the nurse discovered that the ward had expended its supply of the usual antiseptic and so was forced to cleanse the self-inflicted wounds with alcohol. Jones clearly found this quite unpleasant and refrained from head-banging for several days thereafter. When she resumed head-banging, several staff members suggested a revised behaviormodification plan combining the differential reinforcement approach with an aversive element consisting of cleansing the wounds with alcohol immediately after an episode of head-banging. Although there seemed to be good reason to think that the plan would reduce the head-banging, both Jones and her guardian refused to consent to the plan. 
All members of the team agree that this plan presents the best hope of altering the self-injurious behavior, but employing it without permission from both Jones and the guardian violates the Wyatt standard. ${ }^{37}$ Again, the clinician's interests in avoiding potential liability diverge from the patient's interests-the patient would benefit from the program, but the psychologist believes he can best protect himself from liability by refraining from writing such a program.

Brown, an outpatient at a community mental health center, attends weekly therapy because of periodic episodes of anxiety and depression and his life-long inability to maintain a job or a relationship. Recently he has spoken of another patron at a neighborhood bar who has insulted and pushed him. This week Brown states, "But now I got some brass knuckles, so if he pushes me again, I'll cave his face in." When the therapist suggests that she might have to warn the potential victim, Brown pounds his fist on the table, yelling, "If you ever tell anyone I come here, I'll never come back." The therapist believes from past experience with Brown that she can best serve his interests and those of the public by maintaining therapeutic contact, calming him down, and talking him into leaving the weapon at home, but she also believes that she can best avoid liability under Tarasoff ${ }^{38}$ by warning the potential victim.

The Smith, Jones, and Brown cases all exhibit a common structure. In each case, a clinician encounters circumstances in which the interests of his patient and the community diverge from his own, and this divergence is a product of a crystallized legal standard that defines his potential liability, at least as he understands it, in a manner that conflicts with his patient's interests or those of the community. The clinicians in these cases believe that they can best protect themselves from liability under these standards by practicing in a manner other than that which would promote the interests of their patients or of society.

Some evidence indicates that this response to conflict between legal standards and patients' interests is not merely hypothetical. Several states have responded to the Wyatt conditions on patient work by eliminating all patient work programs in state institutions. ${ }^{39}$ At least one commentator reports that legal regulations and court orders regarding 
electroconvulsive therapy (ECT) in public hospitals have led many clinicians and hospitals to abandon this mode of treatment, even when it is clinically indicated. These data suggest that regulation has produced a two-tiered system of care in which ECT is available to voluntary patients in private hospitals but unavailable to poor patients who receive care at public facilities that have abandoned the procedure in order to avoid liability. ${ }^{40}$ While it is conceivable that these public institutions have decided that work programs and ECT are never in the best interests of their patients, it seems much more likely that they have abandoned these treatment modalities in order to avoid legal liability under crystallized standards.

The second way in which this divergence of interests can motivate clinicians to protect themselves through conduct contrary to the purpose of the negligence standard involves avoidance of the potentially troublesome circumstances in which the crystallized duty is likely to arise. A therapist in an outpatient clinic, for example, might take steps to avoid hearing threats, such as those uttered by Brown, that would give rise to the duty to warn. She might generally avoid patients who seem angry as well as those with a history of violence. Alternately, she might subtly discourage patients from revealing information that would give rise to the duty by explaining at the outset of her initial interview with each new patient that she would have to notify police or others if the patient says he is going to do anything dangerous.

Such information-avoiding behavior would not even have to be intentional. The therapist who believes that any threat will legally obligate him to issue a warning might find that prospect so disturbing that his response to verbalizations of anger might unintentionally discourage such revelations. Suppose, for example, that a therapist who responded with careful attention and empathy to most patient communications became apprehensive and, consequently, less empathetic as soon as the patient began to verbalize anger. Such a 
response might distort the therapeutic process in such a way as to preclude sufficient disclosure to give notice of the danger, and thus of the duty.

Behavior-modification programs involving aversive stimuli are most often appropriate with severely regressed or retarded patients who engage in injurious behavior that is resistant to other forms of treatment. A clinician can avoid the type of potential conflict that arises in the Jones case by refusing to work in programs that treat such patients. Thus clinicians might best avoid these potential conflicts by avoiding just those patients and clinical settings that one would ordinarily think are most important to the public interest.

It is tempting to respond to these cases by reminding the therapists described above that any clinician who abandons his responsibility to his patients in order to protect his own interests is violating his most fundamental duty. The clinician accepted the responsibility to give priority to his patients' interests when he entered the profession, and therefore he has no business acting to protect his own interests when these conflict with those of a patient.

While this may well be a legitimate response for many parties to advance, it is a difficult one for the legal system to sustain. The legal system employs the law of tort for the specific purpose of motivating clinicians through appeal to their selfinterest. It would be odd indeed for the legal system to criticize clinicians for responding to the legal system in the very manner that the system is designed to enforce. This irony introduces the second and perhaps most fundamental difficulty produced by crystallized negligence standards for clinical practice.

- The fundamental tension
The previous section contends that crystallized standards of care can promote undesirable conduct under certain circumstances. Those who are familiar with tort law will not be surprised by this claim, but some might argue that crystal- 
lized duties remain justified if they generally promote socially beneficial behavior in the long run. This section identifies, however, a more fundamental tension in the attempt to enforce clinical practice through negligence law.

Certain professional relationships are fiduciary ones, and those who engage in these professions incur a fiduciary duty to their clients. Among health care professions, the fiduciary duty has been most frequently and forcefully articulated regarding physicians, but it also applies to other clinicians. ${ }^{41}$ A fiduciary is "a person having a duty, created by his undertaking, to act primarily for another's benefit in matters connected with such undertaking." ${ }_{42}$ The fiduciary must pursue this undertaking solely for the benefit of the other, disregarding his own interests. The fiduciary must also avoid placing himself in a position in which his personal interests or those of third parties might conflict with those of the person to whom he owes the fiduciary duty. ${ }^{43}$ Fiduciary relationships include "those informal relations which exist wherever one man trusts in or relies upon another. One founded on trust or confidence reposed by one person in the integrity and fidelity of another . . . the relation can be legal, social, domestic, or merely personal." "4

In summary, the fiduciary duty arises when one person trusts in or relies upon another's integrity or fidelity and hence becomes dependent upon or vulnerable to the other's performance. The clinician's fiduciary duty is a product of the patient's trust in and dependence upon the clinician's skill and care. The duty requires that the practitioner pursue the clinical relationship solely for the best interests of the patient, without regard for his own interests. ${ }^{45}$ The cases described above, in which crystallized standards of care create a conflict between the clinician's interests in avoiding liability and the interests of the patient, are ones in which tort law exerts pressure on the clinician to act in a manner that is contrary to this fiduciary duty. Under these conditions, the substantive law imposes on the clinician a fiduciary duty to 
consider only his patient's interests, and it actively creates an incentive structure that promotes violations of that duty.

These cases reflect the fundamental tension that pervades the entire enterprise of enforcing appropriate clinical practice through tort. Negligence law attempts to guide behavior by structuring liability in a manner that motivates actors to conform to reasonable standards of care by appeal to their self-interest. The fiduciary duty requires that the clinician ignore self-interest and act purely for the patient's interest. When the law attempts to reinforce the fiduciary relationship through tort liability, it attempts to motivate the practitioner, through appeal to his self-interest, in such a manner as to prevent him from responding to appeals to his self-interest. That is, the law directs the clinician not to respond to that set of influences that includes this very legal directive. In effect, the court says to the clinician, "Do not attend to that class of considerations that includes this one."

This tension creates the following dilemma: (1) Negligence law attempts to protect and reinforce the fiduciary relationship by directing the clinician's conduct in that relationship through appeals to his self-interest. (2) Either the clinician responds to this directive or he does not. (3) If the practitioner does not respond to the law's directive, then it cannot protect or reinforce the fiduciary relationship. (4) If the clinician does respond to the law's directive, then the law has successfully directed the clinician's attention to his own selfinterest, thus undermining the fiduciary relationship. Therefore the law's directive either fails to protect and reinforce the fiduciary relationship or it actively undermines it. In short, attempts to protect or reinforce the fiduciary relationship between clinician and patient through tort liability are inherently self-defeating. ${ }^{46}$

While this dilemma pervades the entire enterprise of enforcing the therapeutic relationship through negligence liability, it takes a harmless form under most circumstances. Under 
ordinary conditions, sentence (3) will apply, in that the practitioner will not respond to the influence of tort law because no indicators of unusual tort liability will arise. The practitioner will simply practice in an ordinary competent manner without considering tort liability because no circumstances suggest that potential liability is imminent. In these conditions, negligence law will not actively protect or reinforce the fiduciary relationship, but that fact will be harmless because such reinforcement will be unnecessary. The dilemma takes on a more malignant form, however, when sentence (4) applies. When the clinician's tort-driven interests as defined by a crystallized standard diverge from the patient's interests and the clinician conforms to the crystallized standard in order to avoid liability, then negligence law actively undermines the fiduciary relationship it is intended to reinforce.

Many circumstances can produce conflicts between the fiduciary's duty and his self-interest. It is important to recognize, however, that the type of conflict described in this paper is created by the law that is intended to protect and reinforce the fiduciary relationship. This tension may arise for practitioners of any profession that involves a fiduciary relationship. The nature of psychotherapy may render it particularly problematic, however, for mental health clinicians. Because of the importance of the therapeutic relationship to the therapeutic process, apprehension regarding tort liability may undermine the fiduciary relationship between patient and therapist even in cases in which the therapist does not act in a manner contrary to the patient's interests.

C. Psychotherapy and crystallized standards of care
Outcome research increasingly supports the contention that psychotherapy produces statistically significant and clinically meaningful improvements for patients. These positive results tend to last and to exceed the effects of placebo or pseudotherapy control groups. Although certain theoretical approaches secure superior effects for specific types of problems under certain conditions, no particular school of 
therapy is consistently superior to the competitors. The therapist-patient relationship plays a central role in successful therapy. Mutual acceptance and trust characterize effective therapeutic relationships. ${ }^{47}$ Therapist credibility and trustworthiness contribute significantly to the positive outcome of successful therapy. Effective therapy occurs when the patient and the therapist perceive each other as being on the same "wavelength"- when the therapist and the patient share a mutual perception of understanding and trust. Patients improve as a result of therapeutic relationships in which they perceive an interest in and endorsement of their well-being. ${ }^{48}$

In summary, psychotherapy is generally effective, and the quality of the therapeutic relationship contributes significantly to success. Effective therapeutic relationships are characterized by mutual trust and acceptance as well as by the patient's perception that the therapist cares about and pursues the patient's interests. It is reasonable to expect, then, that any disruption of this relationship impairs the effectiveness of therapy. Notice that the effective therapeutic relationship has certain qualities in common with the fiduciary relationship. Trust and a primary concern for the patient's well-being are central to both. This suggests that any influence that disrupts the fiduciary relationship would also impair the therapeutic relationship and therefore the effectiveness of the therapy.

Two plausible assumptions can be made about mental health practitioners. First, most are basically honest and responsible. They generally attempt to fulfill their responsibilities, and they realize that this involves pursuing the best interests of their clients. Hence, they usually practice their profession in a manner intended to promote their patients' well-being. Second, few are heroic. Although they generally pursue their patients' interests, they will probably not do so at the cost of absorbing substantial personal harm or risk. ${ }^{49}$ 
Given these two assumptions, most clinicians will pursue the therapeutic relationship in a manner that will promote effective therapy and fulfill their fiduciary responsibilities under most conditions. They will not do so, however, at the cost of substantial personal cost, including the risk of tort liability. That is, concern about tort liability can undermine the ordinary clinician's devotion to both the fiduciary duty and the therapeutic project when conflicts occur between the standard of care for tort liability and the conduct likely to promote effective therapy. If tort liability sometimes undermines the fiduciary relationship in the manner suggested, and if the relationship carries the significance for effective therapy that it apparently does, then tort liability probably also impairs effective therapy. In such cases, tort liability will undermine the very process it is intended to promote. This effect is not necessarily limited to those cases in which the therapist actually sacrifices the patient's interests to protect himself from tort liability. If the clinician is sufficiently concerned about tort liability to conduct the therapeutic relationship with a wary eye toward protecting his own interests regarding liability, that attitude may be sufficient to dilute the therapist's apparent trustworthiness and concern for the patient's welfare and thus to undermine the therapeutic relationship.

\section{Discussion and recommendations}

At first glance, these arguments may seem to generate the intuitively implausible claim that no one should ever be held liable in tort for violating a fiduciary duty. This does not follow, however; these arguments identify a tension rather than a contradiction inherent in the attempt to protect and reinforce fiduciary relationships through tort liability. This tension does not infect all cases. 
It may be helpful to think of the person charged with a fiduciary duty as making decisions relevant to that responsibility at two levels of generality - the specific level and the strategic level. At the specific level, the fiduciary must make choices that directly affect the interests of the party whose well-being he is charged with protecting. For example, a guardian may have to decide whether to approve surgery for an incompetent ward; a trustee may have to decide whether to invest the beneficiary's funds; or the clinician may have to decide whether to write a treatment plan for Smith that includes unpaid labor in the hospital.

In some cases, however, the fiduciary's interests may conflict with those of the beneficiary at this specific level. Suppose, for example, that a trustee badly needs a loan to avoid the collapse of his own business, while his incompetent ward would benefit most from a safe long-term investment. In such a case, the trustee's self-interest motivates him to lend the ward's funds to his own business, while his fiduciary duty demands that he invest those funds in some safer long-term alternative. The law requires that fiduciaries resolve such conflicts of interest at the specific level in favor of their beneficiaries, and it enforces this requirement by holding liable in tort fiduciaries who advance their own interests at the expense of their beneficiaries. By doing so, the law attempts to motivate fiduciaries through appeal to their selfinterest at the more general strategic level. At this strategic level, fiduciaries adopt an attitude or decision-making strategy for decisions at the specific level. By imposing tort liability on those fiduciaries who attend to their own interests at the level of the specific decision, the law can manipulate the interests of fiduciaries at the more general strategic level in such a manner as to motivate them to adopt a general strategy of ignoring their self-interest when they make specific decisions. By attaching liability to self-regarding decision-making strategies, the law causes the fiduciary's interests to converge with those of the beneficiary, because 
the fiduciary can promote both the beneficiary's interests and his own by making specific decisions without regard for his own interests.

While this convergence of the clinician's interests with those of the patient obtains in principle, it holds in practice only if one makes an additional assumption. Interests converge in this manner only if courts' retrospective determinations of ordinary care and competence usually coincide at least roughly with clinicians' prospective judgments. That is, clinicians will be well advised to forgo considerations of selfinterest at the level of specific clinical decisions only if they have reason to believe that the actions they take on this basis will generally receive retrospective approval by courts applying the same standard. If, however, practitioners believe that court determinations of malpractice are determined primarily by hindsight bias, client or bar litigiousness, perceptions of deep pockets, or any additional factor other than their own due care, then tort liability does not motivate them to adopt the strategy of ignoring their own interests at the level of specific decisions. Rather, it motivates them to adopt the strategy that they deem most likely to protect them from whatever factors they believe to be determinative of court decisions.

We assume for the sake of argument that courts' retrospective evaluations of due care generally correspond at least roughly to clinicians' prospective judgments of responsible practice. This assumption does not deny the possibility of substantial divergence between the criteria applied by clinicians and those applied by courts. Significant disparity may result from factors such as the effects of hindsight bias, particular fact patterns, or differences in error preferences. We assume only that the criteria of due care applied by courts and clinicians correspond to a degree sufficient to render it prudent for most clinicians to adopt the general strategy of making most specific clinical decisions with their attention directed primarily toward their clients' interests. ${ }^{50}$ 
Insofar as this assumption applies, the law can reinforce the -fiduciary duty through appeal to the fiduciary's self-interest without contradiction, because the fiduciary is required to forgo self-interest at the specific level and the behaviorguiding influence of potential tort liability appeals to the fiduciary's self-interest at the more general strategic level. ${ }^{\text {st }}$ This approach remains viable, however, only so long as the traditional OCC standard is applied. Only with the OCC standard and this third assumption can the clinician protect his own interest regarding tort liability by disregarding it and conducting his clinical practice in a manner intended to further the interests of his patients.

Serious conflicts can arise for clinicians, however, when the law departs from the OCC standard and establishes crystallized standards for tort liability at the level of specific clinical decision. Then the clinician cannot confidently protect himself by disregarding self-interest in favor of client interest when making specific decisions. The practitioner who directs his attention solely to the patient's welfare might make decisions that violate crystallized tort duties and hence his own legally engendered interest in avoiding liability. If the law adopts crystallized standards of care, the prudent clinician cannot safely set aside his own interests and pursue the fiduciary duty with confidence that careful attention to the fiduciary responsibilities will also protect his own interests.

When the law adopts crystallized standards, the practitioner must choose one of two general strategies. First, he can adopt the heroic course, ignoring the potential threat to his own interests and pursuing the fiduciary duty at his own peril. Second, he can adopt the prudent alternative, practicing his profession with an ongoing vigilance toward his own interests, pursuing his clients' welfare whenever he can do so without placing himself at serious risk, but sacrificing a patient's interests (or those of the community) when doing so fulfills crystallized duties. Given the assumption that most 
clinicians are responsible but not heroic, it is reasonable to expect many clinicians to take the prudent course.

The prudent course generates the dangers described in section II in that clinicians may take action to protect themselves at the expense of their patients. Alternately, the mere fact that clinicians are practicing with a wary eye toward liability may dilute the therapeutic relationship in a manner that impairs therapeutic effectiveness. As discussed previously, the legal system should be very hesitant to criticize any clinician who attends to his self-interest in these circumstances, because the clinician would be responding to legal standards specifically designed to motivate the practitioner by appeals to his selfinterest. For the legal system to criticize the clinician under these conditions would be for the law to berate the practitioner for failing to heroically resist the pressures created by the law itself.

The argument advanced thus far suggests that if one assumes that most clinicians are responsible but not heroic and that they have good reason to think that court determinations of negligence will coincide at least relatively well with their own judgments of good practice, then (1) courts can enforce the practitioner's fiduciary duty through tort liability without contradiction, provided that they apply the traditional OCC standard, and (2) crystallized duties create a fundamental tension that renders that enforcement project inherently selfdefeating.

Does our opposition to crystallized duties force us to accept the counter-intuitive proposition that courts should not treat physical assault of the patient by the therapist as per se improper? ${ }^{s 2}$ Recall the underlying problem: tort law is a legal institution employed to protect and reinforce the fiduciary relationship, but it can combine with crystallized standards of care to undermine that relationship. Certain conduct by clinicians, however, demonstrates that those practitioners have already lost sight of or abandoned the fiduciary rela- 
tionship. If conduct, such as assault, is such that it cannot plausibly fall within the scope of responsible clinical practice, then a crystallized standard that precludes it will apply only when the fiduciary relationship has already been lost. The arguments presented above are predicated on the commonplace assumption that most clinicians are honestly motivated and responsible, not on the implausible assumption that all are. Crystallized duties that are limited to conduct noncontroversially beyond the scope of responsible practice do not undermine the fiduciary relationship, because they apply only when such a relationship does not exist. The responsible clinician can safely ignore these crystallized standards and pursue the therapeutic project for the benefit of the patient with confidence that he is not putting himself at risk.

These arguments therefore support the conclusion that tort liability based on the traditional OCC standard, possibly supplemented with crystallized duties that apply only to conduct that clearly falls beyond the pale of responsible practice, is consistent with the legal purpose of promoting and reinforcing.the fiduciary therapeutic relationship. Crystallized duties that do not clearly fall beyond the scope of responsible practice in all cases, however, undermine the fiduciary relationship they are intended to protect.

Some critics might accept these arguments as applied to per se rules but contend that duties such as the Tarasoff duty to warn or the Wyatt standards regarding work or behavior modification should be accepted as presumptive evidence of malpractice. These critics might argue that the courts ought to treat conduct violating these standards as establishing a rebuttable presumption of malpractice. The clinician would then have the opportunity to demonstrate in court that the conduct violating these standards was justified in that particular case. 
This objection fails, however, because it assumes that clinicians incur substantial losses only when they lose a malpractice action and hence that only the prospect of losing such a suit will motivate them to turn their attention from their patients' interests to their own. Clinicians incur substantial costs, however, when they are sued, and these costs remain even if the clinician prevails. ${ }^{33}$ Thus, they are motivated to avoid being sued.

Clinicians can reasonably expect plaintiff's attorneys to be more willing to bring suit merely on the basis of a violation of a standard if that violation raises a rebuttable presumption of malpractice, shifting the burden of persuasion to the defendant, than they would if that violation did not raise the presumption and therefore left the burden on the plaintiff. Given this expectation and clinicians' motivation to avoid being sued, accepting violations of standards as presumptive of fault generates the tension between clinicians' fiduciary duty and their self-interest as defined by the standard. In circumstances in which clinicians believe that violating the standard would promote their patients' interests, the patients' interests support violations of the standard, but the practitioners' tort-driven interests support conformity.

Consider the ramifications of these conclusions for professional organizations as they publish guidelines for professional practice. Establishing guidelines and recommendations for professional practice seems to be an ordinary and even expected function of professional organizations. If these organizations publish such recommendations, however, and find that their guidelines are used to support crystallized duties that their members are then held liable for transgressing, then they may become understandably hesitant to advance such guidelines.

The American Psychiatric Association's standards for psychiatric treatment facilities appear to demonstrate this pattern of legally induced professional reticence. In 1958 the 
association published recommended staffing standards for hospitals and clinics that included tables of staffing ratios for public and private facilities. ${ }^{\$ 4}$ It represented these standards as requirements for active treatment and humane care. ${ }^{5 s}$ After the 1966 Rouse v. Cameron ${ }^{\text {s6 }}$ court referred to these standards as evidence supporting a finding of inadequacy in the treatment provided by some facilities, however, the association in 1969 published revised standards without the staffing ratios. The association characterized these revised standards as relevant to the pursuit of professional excellence and stated that the tables of staffing ratios were omitted because it was impossible to set forth meaningful national ratios. ${ }^{57}$

Professional organizations seem to face the following dilemma. If they produce recommendations for clinical practice, they run the risk that courts may turn these into crystallized rules and use them as criteria of liability in a way that actually frustrates the practice of the profession and undermines the fiduciary relationship. If they do not publish such guidelines, however, they fail to fulfill one of their ordinary functions, and they leave the courts to establish standards with no guidance from the profession.

Professional organizations might be tempted to respond to this dilemma by formulating guidelines for the very purpose of preempting judicial evaluations of due care by codifying their self-interest and insulating clinicians from liability. They might consider establishing guidelines designed to provide their members with concrete rules that individual clinicians could use as evidence of due care in the form of compliance with professional standards. By doing so, these organizations might effectively establish conventions that courts would adopt as crystallized and therefore predictable standards of care, but in doing so they would encounter a deep tension with their ethical duty to promote professional practice for the benefit of the patient rather than of the practitioner. Perhaps the analysis presented in this paper 
suggests a more satisfactory method by which professional organizations can avoid this apparent dilemma.

Conduct that falls categorically outside the bounds of responsible practice can be identified as such because crystallized duties regarding this type of behavior do not interfere with competent and careful practice. Professional guidelines will be most helpful, however, when they address treatment methods such as the use of restraints, seclusion, or aversive stimuli, which are controversial but have legitimate applications. Useful guidelines regarding the use of such methods must be written against certain background assumptions regarding training, facilities, immediately available alternatives, and clinical indications. Guidelines should make explicit as many of these assumptions as possible, and they should indicate that they apply only as general principles that should be taken into account when these assumptions are fulfilled. They should also explicitly state that either conformity with these principles or departure from them might be required for particular clinical circumstances. The clinician, therefore, should consider and document the relevant reasons for conforming with or for departing from the guidelines. That is, the mere fact of either conformity or departure should not raise a presumption of either responsible or irresponsible practice without consideration of the reasons cited for taking the action in question.

On this understanding, professional guidelines should not provide concrete rules for practice; rather, they should explain the relationship between various professional practices and relevant clinical circumstances. Clinical practice that either conforms to or departs from the guidelines therefore can be evaluated only by considering the clinician's reasons for acting in light of the explanations provided by the guidelines. 
Some current professional guidelines conform at least generally to this recommendation. A task force of the American Psychological Association charged with evaluating ethical issues in behavior modification rejected fixed standards in favor of a checklist of issues to be considered by clinicians designing behavioral interventions. The checklist is intended to ensure that important issues are considered, not to resolve them. It raises questions about such issues as consent, confidentiality, accountability, and the right to terminate a program, but it does not specify concrete standards for these considerations..$^{38}$

Similarly, an American Psychiatric Association task force on seclusion and restraint has identified general indicators for seclusion and restraint in the form of appropriate purposes, including prevention of harm, protection of property, and facilitation of treatment. The task force explicitly rejected rigid regulations, however, and recognized that individual clinical decisions required familiarity with the specific patient and circumstances. ${ }^{99}$ This task force, like that of the American Psychological Association, suggested guidelines regarding behavior-modification programs that took the form of questions to be raised about the specific treatment plan to be implemented. ${ }^{60}$

Professional standards developed and presented in this manner could provide one source of relevant evidence in a malpractice trial, but they would not provide reasonable grounds for either per se rules or presumptions. In an analogous setting, one commentator has raised the more extreme possibility that the law should prohibit any use of professional standards to establish malpractice liability. ${ }^{61}$ Such a rule might be warranted if it is necessary to insulate the important professional guideline development process from infection by worries over legal liabilities. We will not pursue this proposal in this paper. If courts accepted professional guidelines as relevant evidence, but not as per se or presumptive rules, practitioners might be encouraged to 
employ them as reflective tools for consideration in difficult clinical situations, thus informing their clinical practice and limiting their potential liability.

\section{Conclusions}

Tort law is intended partially to motivate people to fulfill a duty of reasonable care toward others by creating an interest for the actor that converges with the interests of others. Under certain circumstances, this purpose of tort law can create a paradoxical tension in that crystallized duties of care intended to enforce the fiduciary duty can actually undermine the fiduciary relationship. The potential for this effect arises whenever the legal system enforces a fiduciary duty through the mechanism of tort law, but it becomes particularly acute when courts establish crystallized duties as either per se rules or presumptive standards.

While this tension may interfere with various fiduciary duties, the problem may be exacerbated for psychotherapists for the following reason. For some professions and some fiduciary duties, it might only be important that the fiduciary act in the best interests of the beneficiary. For example, if an attorney acts as a trustee for the estate of an incompetent ward, the purpose of the fiduciary duty may be satisfied so long as the trustee manages the estate for the best interest of the ward, regardless of the attorney's motivation for doing so. However, if the therapeutic relationship plays as important a role in successful psychotherapy as some sources suggest, it may be important not only that therapists act in their patients' best interest, but also that they do so out of concern for their patients' interests. If so, then a legal institution that enforces the fiduciary duty through appeal to the fiduciary's self-interest may undermine its own purpose even if it does not produce actions that frustrate the fiduciary responsibility. 
This analysis suggests the following steps as means of reducing this paradoxical tension: (1) Although crystallized standards of liability might be desirable from the point of view of the practitioner as a means of increasing predictability, courts should generally establish such duties only for conduct, such as assault, that clearly falls beyond the scope of responsible practice. (2) In most cases, courts should apply the traditional OCC standard. (3) Courts should accept guidelines produced by professional organizations as relevant evidence regarding malpractice but not as establishing per se or presumptive rules. (4) Professional organizations generally should not publish concrete rules of practice, but they should frame guidelines in the form of explanations of the relationships among various practices and relevant clinical conditions. They should explicitly recognize that either conformity to or departure from these standards can constitute responsible practice and that any particular case must be evaluated in light of the practitioner's reasons for acting.

Apart from indisputably irresponsible practices such as assault, both professional organizations and courts should refrain from establishing standards of practice in the form of concrete professional rules or crystallized legal duties. When courts establish crystallized standards regarding practices that do not fall clearly beyond the scope of responsible practice, they risk two potential pitfalls. First, they may create a counter-productive standard in that they may discourage clinicians from practicing in their patients' interests when those clinicians encounter circumstances in which their patients' needs diverge from the crystallized standard. Second, the courts may encourage professional organizations to distort their appropriate function by refraining from developing needed guidelines or by formulating professional standards for the purpose of protecting their members from liability rather than for the purpose of promoting patients' interests. 
This paper has considered a fundamental tension that pervades the entire enterprise of enforcing the therapeutic fiduciary relationship through negligence law. While we advocate primary reliance on the OCC standard rather than on crystallized rules of liability as the most efficacious manner of avoiding the insidious effects of this tension, we do not suggest that the OCC standard resolves all of the substantial problems with tort regulation of psychotherapy. Such regulation remains quite troublesome for several reasons.

To the extent that courts rely on the OCC standard, practitioners remain vulnerable to the effects of idiosyncratic "experts" who are willing to testify regarding "professional standards" known only to them. ${ }^{62}$ In addition, the OCC standard does nothing to alleviate the problem described earlier regarding hindsight bias and the clinician's inability to predict the court's retrospective determinations of reasonable care. ${ }^{63}$ Perhaps courts can correct for the hindsight bias, at least partially, through procedural rather than substantive methods. A comprehensive treatment of the tort regulation of mental health practitioners would extend well beyond the scope of a single paper. Our purpose here has been only to identify and address this tension inherent in the reinforcement of the therapeutic relationship through tort liability.

Notes 1. See generally D. Wexler, Therapeutic Jurisprudence (forthcoming); D. Wexler \& R. Schopp, Therapeutic Jurisprudence: $A$ New Approach to Mental Health Law, in HANDBOOK OF PSYCHOLOGY AND LAW (D. K. Kagehiro \& W. S. Laufer eds., forthcoming).

2. See infra section I for a more complete description of the relevant negligence principles.

3. D. Wexler \& R. Schopp, How and When to Correct for Juror Hindsight Bias in Mental Health Malpractice Litigation: Some Preliminary Observations, 7 BEHAVIORAL SCIENCES AND THE LAW 485 (1989). 
4. Id.

5. Id.

6. N. Poythress, Negligent Release Litigation: A Proposal for Procedural Reform, paper presented at the annual convention of the Association of American Law Schools, New Orleans, Louisiana, January 1989.

7. A. Benedict and M. Saks, The Regulation of Professional Behavior: Electroconvulsive Therapy in Massachusetts, 15 JOURNAL OF PSYCHIATRY AND LAW 247 (1987).

8. A brief terminological note may be helpful. This paper is intended to apply to psychologists, psychiatrists, psychiatric social workers, nurses, and any others who practice professions that involve the delivery of mental health care. We will use the terms "clinician" and "practitioner" interchangeably as generic names for those who practice these professions. We will use the term "psychotherapy" broadly in the sense in which it is not limited to any particular school or approach. It should be understood as roughly synonymous with "mental health care." Finally, this paper will directly discuss only mental health care and practitioners, although the central issues may also apply to certain other professions, including law and medicine.

9. Prosser AND KeEton ON TORTS 5-7 (5th ed. 1984) [hereinafter cited as Prosser].

10. Id. at 171-173.

11. Id. at 16,25 .

12. Id. at 173-175. The conception of an ordinary prudent person employed here is a normative rather than a statistical one. It refers to a hypothetical person who is always as careful as the circumstances warrant, not the average person who occasionally behaves in a careless or forgetful manner.

13. Id. at 185-187.

14. See supra notes 3-7 and accompanying text.

15. Prosser, supra note 9, at 217-219.

16. Helling v. Carey, 519 P.2d 981 (Wash. 1974). See also Gates v. Jensen, 595 P.2d 919 (Wash. 1979). In Salientro v. Nystrom, 341 So. 2d 1059 (Fla. App. 1977), the court found it unnecessary to consider whether radiologists were under a crystallized duty of care, before administering $x$-rays, to ask a woman of child-bearing age whether she was pregnant. 
17. Prosser, supra note 9, at 220-233. To identify a particular type of conduct as negligent per se is to declare conduct of that type as falling below the required standard of care as a matter of law without regard for a jury evaluation of the surrounding circumstances in each individual case. That is, a particular type of activity is considered categorically negligent without regard for the circumstances in which it occurred. A presumption of negligence, in contrast, can be refuted by showing evidence supporting the contention that the conduct was reasonable under the circumstances.

18. J. Wade, An Overview of Professional Negligence, 17 MEMPHIS STATE L. REV. 465, 473-474 (1987).

19. Hammer v. Rosen, 7 N.Y.2d 376, 377, 165 N.E.2d 756, 757 (1960).

20. D. J. Davidoff, THE Malpractice of Psychiatrists 76-77 (1973).

21. S. J. Brakel, J. Parry, \& B. Weiner, The Mentally Disabled AND THE LAW 581 (3rd ed. 1985).

22. Tarasoff v. Regents of University of California, 17 Cal. 3d 425, 551 P.2d 334, 131 Cal. Rptr. 14 (1976).

23. Id. at 431, 551 P.2d at 340, 131 Cal. Rptr. at 20.

24. The California Supreme Court actually handed down two opinions in the Tarasoff matter. In the first, the court articulated a specific duty to warn. Tarasoff $v$. Regents of University of California, 13 Cal. 3d 117, 529 P.2d 553, 118 Cal. Rptr. 129 (1974). Upon rehearing, the court apparently abandoned the duty to warn in favor of a duty to protect. Prudent clinicians ought to understand this de jure duty to protect as a de facto duty to warn, however, for the reasons given in the text.

25. Tarasoff, 17 Cal. $3 \mathrm{~d}$ at 439,551 P.2d at 345,131 Cal. Rptr. at 25.

26. Notice that this duty actually takes a hybrid form. The duty attaches when the therapist knows or should know of the danger. Thus, the court applies the OCC standard to decide whether the duty applies in each case. If the duty applies, however, the acceptable response is crystallized.

This interpretation of the Tarasoff duty as a crystallized duty to warn applies to Tarasoff and to similar opinions that retain the identifiable victim requirement and in practice find that protective steps other than warning are inadequate unless they succeed. Courts in other jurisdictions could adopt variations of the Tarasoff duty measured by the "zone of danger" standard rather than the "identifiable victim" test, and they could interpret other fact 
situations such as to actually accept alternative methods of attempting to prevent expected danger. The interpretation of the Tarasoff duty as a crystallized duty to warn would not apply under these conditions. Frequently, however, cases following Tarasoff have retained the requirement of an identifiable victim. Brakel, Parry, \& Weiner, supra note 21, at 585-87; see, e.g., Brady v. Hopper, 570 F. Supp. 1333, 1339 (D. Col. 1983) (endorsing the "specific threat to specific victim" rule).

27. Wyatt v. Stickney, 344 F. Supp. 373 (D. Ala. 1972) (addressing standards of treatment for the mentally ill); Wyatt v. Stickney, 344 F. Supp. 387 (D. Ala. 1972) (addressing standards of habilitation for the mentally retarded).

28. Wyatt v. Stickney, 344 F. Supp. 373, 381 (D. Ala. 1972).

29. Wyatt v. Stickney, 344 F. Supp. 387, 400 (D. Ala. 1972).

30. Rogers v. Okin, 478 F. Supp. 1342, 1365, 1374 (D. Mass. 1979).

31. Rogers v. Okin, 634 F.2d 650, 657 (1st Cir. 1980).

32. Youngberg v. Romeo, 457 U.S. 307, 323 (1982).

33. See, e.g., Woe v. Cuomo, 729 F.2d 96, 101-107 (2nd Cir. 1984); Rouse v. Cameron, 373 F.2d 451, 457 (D.C. Cir. 1966); New York St. Ass'n for Retard. Child., Inc. v. Rockefeller, 357 F. Supp. 752, 756 (E.D. N.Y. 1973). All three cases evaluate the adequacy of staffing in the respective institutions, partially by comparing them with the guidelines published by various professional organizations. In Albermarle Paper Co. v. Moody, 422 U.S. 405, 430-436 (1975), the Court gave great deference to EEOC guidelines for validation of employment tests, and these guidelines incorporated the American Psychological Association's professional standards for test validation.

34. D. Wexler, Legal Aspects of Seclusion and Restraint, in THE PSYCHIATRIC USES OF SECLUSION AND RESTRAINT 114 (K. Tardiff ed., 1984). Note that Wexler's advice occurs as part of a larger report of a task force of the American Psychiatric Association, to which he served as a legal consultant. Armed with this advice, the task force rejected concrete standards and advanced general guidelines in the form of a list of purposes and issues to be considered when using seclusion or restraint in the clinical setting.

35. Id.

36. See supra notes 27-29 and accompanying text. Wyatt v. Stickney, 344 F. Supp. 373, 381 (D. Ala. 1972). 
37. See supra notes 27-29 and accompanying text for the Wyatt standard for behavior modification with aversive stimuli. See also Wexler, supra note 34 , at 118 , regarding the right to refuse treatment and behavior-modification programs that lack informed consent.

38. See supra notes 22-24 and accompanying text.

39. M. Perlin, The Right to Voluntary, Compensated, Therapeutic Work as Part of the Right to Treatment: $A$ New Theory in the Aftermath of Souder, 7 SETON HALL L. REv. 298, $300 \mathrm{n} 15$ (1976).

40. S. Taub, Electroconvulsive Therapy, Malpractice, and Informed Consent, 15 JOURNAL OF PSYCHIATRY AND LAW 7, 39-42 (1987).

41. Hammonds v. Aetna Ins. Co., 243 F. Supp. 793, 802 (N.D. Ohio, E.D. 1965); Hales v. Pittman, 118 Ariz. 305, 308-309, 576 P.2d 493, 496-497 (1978); Miller v. Kennedy, 11 Wash. App. 272, 282, 522 P.2d 852, 860 (1974); Berky v. Anderson, 1 Cal. App. 3d 790, 804, 82 Cal. Rptr. 67, 77 (1969); S. R. Smith \& R. G. Meyer, LAw, BeHavior and Mental Health 5-6 (1987).

42. BLACK's LAW Dictionary 563 (5th ed. 1979).

43. G. T. Bogert, Trusts 341-342 (6th ed. 1987).

44. BLACK's, supra note 42, at 564.

45. See generally Davidoff, supra note 20 , at $43-60$.

46. Strictly speaking, the Tarasoff duty to warn does not fall prey to this dilemma because the Tarasoff court's decision was not directed primarily toward protecting the fiduciary relationship. Rather, the decision placed a limit on the fiduciary duty "where the public peril begins." However, the same tension underlies the fiduciary duty and the Tarasoff duty. In each case, the clinician is expected to act for the interests of some other party (the patient or the public) rather than for self-interest. The Tarasoff duty, like the fiduciary duty, is predicated upon the vulnerability of the other parties and on the clinician's putative ability to protect them through warnings. Thus the Tarasoff duty is similar to the fiduciary duty in both nature and origin, and it can create a conflict between the interests of the intended beneficiaries and the clinician's interests in avoiding liability when the crystallized standard seems unlikely to protect the interests of those intended beneficiaries.

47. M. Lambert, D. Shapiro, \& A. Bergin, The Effectiveness of Psychotherapy, in HANDBOOK OF PSYCHOTHERAPY AND BEHAVIOR Change 157-211 (S. Garfield \& A. Bergin eds., 3rd ed. 1986) [hereinafter "HANDBOOK"]. 
48. L. Beutler, M. Crago, \& T. Arizmendi, Therapist Variables in Psychotherapy Process and Outcome, in HANDBOoK, supra note 47, at 280-281; D. Orlinsky \& K. Howard, Process and Outcome in Psychotherapy, id. at 327-352.

49. These are generally noncontroversial assumptions that one could make about most members of most professions. They do not attribute any unusual characteristics to mental health professionals.

50. This assumption does not preclude the possibility that clinicians will perceive significant divergence between their own conceptions of responsible practice and those that the courts apply in certain circumstances. Although the text discusses this issue in terms of the actual correspondence of clinicians' criteria of due care with that of the courts, the clinicians' perception of correspondence may actually be the critical issue.

Prudent clinicians who perceive a general correspondence of criteria with significant exceptions would understand that their own interests generally converge with those of their patients, and they would exercise reasonable care in pursuing their patients' interests with some confidence that they were also protecting themselves. They might take some steps, however, to correct for those extraclinical factors that seem to influence court decisions. If, for example, clinicians fear being judged by the hindsight bias if a depressed patient commits suicide following release, they might behave quite conservatively in releasing such patients, even when they believe that early discharge is clinically warranted.

While the earlier assumption that most clinicians are responsible but not heroic seems to be a safe one, the assumption that clinicians generally perceive a reasonable correspondence between their conception of due care and that of the courts is much more controversial. This, however, is a separate problem that will not be addressed here.

51. Notice that this picture of fiduciary decisions occurring at two levels of generality does not suggest that the fiduciary's concern for the patient is shallow, hypocritical, or unnaturally divided into two levels of consciousness. The clinician who is honest and responsible but not heroic would probably be happy to discover that the law allows her to put aside her own interests and direct her attention toward her clients' welfare with confidence that she is not placing herself at risk by doing so. Her situation would be analogous to that of the business person who honestly concentrates on promoting customer satisfaction on the reasonable expectation that this attitude is compatible with long-term selfinterest.

52. See supra note 19 and accompanying text. 
53. There are several sources of this loss. First, the process of engaging in the uncertain legal battle requires considerable time and money and produces anxiety. Second, clinicians are likely to lose referrals while the outcome is in doubt and afterwards, as some people operate on the assumption that where there is smoke, there is fire. Finally, control of the case will probably rest in the hands of the insurance company, raising the possibility that the company may settle the case for financial reasons, leaving the appearance of fault even if there was none. For all of these reasons, the prospect of being sued is sufficient to divert clinicians' attention from their clients' interests to their own.

54. American Psychiatric Association, STANDARDS FOR HOSPITALS AND ClinICS 61-62 (1958).

55. Id. at 7.

56. Rouse v. Cameron, 373 F.2d 451 (D.C. Cir. 1966).

57. American Psychiatric Association, STANDARDS FOR PSYCHIATRIC FACILITIES, vii (1969); see also Rouse v. Cameron, 373 F.2d 451, 457 (D.C. Cir. 1966); D. Wexler and S. Scoville, The Administration of Psychiatric Justice: Theory and Practice in Arizona, 13 ARIz. L. REV. 1, 231-232 n68 (1971).

58. S. Stolz, Ethical IsSUES in BeHAvior MOdification 101-114 (1978).

59. T. Gutheil \& K. Tardiff, Indications and Contraindications for Seclusion and Restraint, in Tardiff, supra note 34, at 11-18.

60. R. Liberman \& S. Wong, Behavioral Analysis and Therapy Procedures Related to Seclusion and Restraint, in Tardiff, supra note 34 , at $45-48$.

61. Professor Schneyer has raised this issue in his discussion of the judicial use of legal ethical standards in setting the standard of care in lawyer malpractice cases. After carefully documenting instances of "defensive ethics" that permeated the process of the development of the American Bar Association's Model Rules of Professional Responsibility (e.g., deleting a provision that lawyers be "efficient" for fear that inefficiency would then constitute malpractice; dropping language about lawyers being able to work only on matters in which they can act with "adequate competence" on the grounds that such language might imply that general practitioners lack competence for some tasks; and considering the adoption of "safe harbors" of lawyer behavior so lawyers would clearly know certain actions would be regarded as appropriate), Schneyer asks: "In the interests of promoting the development of sound ethical standards, should the law prohibit the use of professional ethics rules to establish malpractice liability, just as in negligence cases it excludes evidence of subsequent repair in 
order to promote the making of repairs?" T. Schneyer, Professionalism as Bar Politics: The Making of the Model Rules, 14 LAW AND SOCIAL INQUIRY 677 (1989).

One potential complication with this approach in the mental health law area, however, is that it might disenfranchise professional organizations from having input on the setting of standards of due care, and it might elevate through default the idiosyncratic views of individual experts and treatise writers. For if professional guidelines are inadmissible as evidence of the appropriate standard of care, the parties will still need to contest the appropriate OCC standard, and they will have to do so through testimony and writings that do not represent the guidelines of professional organizations.

At least one court has accepted police department guidelines as relevant evidence in a negligence case under a California statute, rejecting the argument that accepting the guidelines as evidence of negligence would discourage police departments from developing such regulations. Peterson v. City of Long Beach, 24 Cal. 3d 238, 594 P.3d 477, 155 Cal. Rptr. 360 (1979).

62. See, e.g., McIntosh v. Milano, 403 A.2d 500, 506 (N.J. 1979) (the majority describes testimony of the plaintiff's expert that seems to suggest that professional standards recognize any violent fantasies as highly reliable indicators of dangerous behavior).

63. See supra notes 3-7 and accompanying text. 
